\title{
Processing of a Multi-representational Science Passage by ESL Learners
}

\author{
Nurjanah Mohd Jaafar ${ }^{a}$ \\ nurjanah@ukm.edu.my \\ Centre for Research in Language \& Linguistics, \\ Universiti Kebangsaan Malaysia, Malaysia \\ Siew Ming Thang \\ siewming.t@help.edu.my \\ ELM Graduate School, HELP University, Malaysia
}

\begin{abstract}
Verbal input is integral and is the core component in any language learning materials. As such, despite the incorporation of non-verbal input to facilitate language learning, language learners, more often than not, give attention more to the verbal components as opposed to the non-verbal ones. This paper reports on a study undertaken to examine 28 ESL undergraduates' eye fixations when reading a science passage in English with an accompanying diagram. The data collection involves two stages. The first stage concerned the reading of the science passage and the second stage comprised short retrospective interviews conducted to explore the reasons behind the learners' processing. Results of the eye tracking analysis indicate that similar to the processing of language learning materials, the ESL learners' processing of the science passage was also mainly focused on the text (henceforth, "heavily text-based"). Findings from the retrospective interviews indicate that although a heavily text-based processing strategy was evident, most of the learners found the graphic input helpful. Analysis of the interviews also revealed that some learners were not aware of the strategies that they employed during the reading process. Although the eye tracking data imply that the ESL learners lacked the awareness and strategy to read and process multi-representational science texts in English effectively, the interviews suggest that they were aware of the potential and benefits of processing the accompanying diagram for overall comprehension. Effective design principles for multi-representational materials are suggested to promote more strategic processing among learners.
\end{abstract}

Keywords: multiple representations; ESL learners; processing science texts; eye tracking; interviews

\section{INTRODUCTION}

The use of multiple representations is not new in teaching and learning. In the teaching and learning of a second language in particular, various instructional and learning materials are incorporated with the commonly used verbal representations such as written and spoken texts, and graphic representations such as photos and videos resulting in products that are lauded as effective and contextually rich (Perez et al., 2013). In general, such multi-representational materials are used to provide the language learners with comprehensible input to facilitate meaningful engagement with the L2 and to elicit from the language learners comprehensible output (Plass \& Jones, 2005).

Various studies have identified the contributing role of multiple representations in the learning of a second language (henceforth, L2) and its various competencies. In the teaching and learning of vocabulary, for instance, in addition to verbalising an L2 word to help learners

\footnotetext{
${ }^{a}$ Main \& corresponding author
} 
acquire its phonological form, exposing learners to corresponding pictures can facilitate meaning acquisition (Bisson et al., 2014; Carpenter \& Olson, 2012). Incorporating multimedia glosses that present brief explanation of difficult lexical items in the form of audio, picture and/ or text can also facilitate reading comprehension in addition to vocabulary acquisition (Plass \& Jones, 2005).

Although previous works have established that multiple representations do facilitate L2 acquisition and its competencies, another issue that warrants an equal amount of attention is whether or not L2 learners do use the additional representation(s). It is therefore important to examine the processes that take place during learning in addition to examining the outcomes of learning. One way to do this is by examining the learners' gaze behavior which can offer researchers moment-to-moment indication of the learners' cognitive processes (Rayner, 2009). Several eye tracking studies have found that graphics in addition to text were indeed fixated or attended to during the processing of multi-representational language learning materials (Bisson et al., 2014; Tragant Mestres \& Pellicer-Sánchez, 2019; Warren et al., 2018). However, these graphics in general were processed to a less extent when compared to the text. In eye-tracking studies, the extent of processing is usually measured using the number of fixations (fixation count) as well as the length of fixations (fixation duration) with higher versus lower values indicating more processing.

In the case of reading science texts with diagrams, the same phenomenon, i.e., the tendency of readers to process the text more than the diagrams, was found in studies conducted on learners reading in their mother tongue (Hannus \& Hyönä, 1999; Mason et al., 2013, 2015; Schmidt-Weigand et al., 2010). However, we are not aware of any studies that look into this issue in L2 reading, especially in the Malaysian context. Hence, this paper presents a study that investigated the reading of a science passage with a diagram by Malaysian ESL learners. A science passage was chosen because in the domain of science, graphics play many pedagogical functions in conjunction with verbal input (Rau, 2017; Stieff et al., 2011). Graphics are used as text adjuncts to make the text more concrete (as in the case of representational graphics), to make the text more coherent by arranging text contents into a structured framework (as in the case of organisational graphics), and to clarify difficult texts (as in the case of interpretational graphics) (Levin et al., 1987). Many science domains require learners to comprehend and integrate text and graphics to gain a cohesive mental model of the domain being learned (Hegarty \& Just, 1993; Renkl \& Scheiter, 2015). As such, we would like to find out what kind of processing Malaysian ESL learners would utilize when reading such materials and the reasons behind it. In addition to contributing to the literature on multiple representations in the L2, this information would allow us to identify whether or not the ESL learners are using the right strategy to learn from such materials.

\section{PROCESSING MULTIPLE REPRESENTATIONS}

In the realm of L2 acquisition, Plass and Jones (2005), through their integrated model of L2 acquisition with multimedia, proposed that representations that are additional to the text can provide the language learners with comprehensible input, facilitate meaningful interaction with the L2, and elicit comprehensible output in the L2. In each of these three phases, the L2 learners are engaged in various cognitive processes, all of which can be facilitated by multiple representations. When a verbal input is presented to the L2 learners, they would need to attend to relevant aspects of the L2 first. This selection/apperception process can be facilitated when another representation, a picture for instance, is included in addition to the verbal input. To illustrate, an L2 aural input played in a listening class can be made more comprehensible by accompanying it with a relevant video. 
Similarly, a variety of representations are available in the various domains of science. More importantly, each representation is commonly used for functional purposes and their combination, among others, adds value to learning (Rau, 2017; Stieff et al., 2011). Multiple representations in the teaching and learning of science, therefore, appear to serve rather different purposes from the ones used in the teaching and learning of an L2. Furthermore, given the pedagogical functions of multiple representations in the domain of science, learners are often encouraged to comprehend and integrate input from the various representations. This way, instead of having a variety of mental models, learners can form one that is coherent and integrates input from the various representations.

The process of constructing this mental model was documented in detail in a seminal study in which a written description of a pulley system accompanied by a corresponding diagram was presented to 10 members of a university community (Hegarty \& Just, 1993). Using an eye tracker, the researchers were able to track the participants' eye fixations and movements while reading. They discovered that the participants first attended to the textual description and processed it incrementally. This was done by reading or rereading the textual description. Information was therefore integrated at a text-based level first. The readers then proceeded to form a spatial mental model with the support of the diagram. A spatial mental model contains information about spatial relations of the object being described. At this point, the participants switched from the textual description to the corresponding parts of the pulley system in the diagram. The switch between the text and the diagram was noted to be highly interleaved. After the participants inspected the graphic component, they would resume reading about the next components of the pulley system from the text. This process suggests that the processing of such materials is often text-guided, in which readers would first read the textual description before inspecting the diagram. The text is also processed extensively so that the readers are able to form a global understanding of the content.

Although the process that Hegarty and Just (1993) documented above has been replicated in other studies (see Bartholomé \& Bromme, 2009; Hochpöchler et al., 2013), an issue that needs to be pointed out is the tendency of many readers to process the text so extensively that they neglect the diagram. We have mentioned earlier that a similar tendency was observed among L2 learners when engaged with language learning materials (Bisson et al., 2014; Tragant Mestres \& Pellicer-Sánchez, 2019; Warren et al., 2018). In addition to language learning materials, this tendency was also observed when ESL learners were reading narratives in English (Pellicer-Sanchez et al., 2018; Mohd Yusof et al., 2020).

It is ironic that this heavy text-based processing similarly applies in the domain of science considering how crucial both text and graphics are in mastering complex and abstract scientific concepts (Hannus \& Hyönä, 1999; Schmidt-Weigand et al., 2010). This is particularly important because failure to attend to graphics sufficiently, which can potentially deter readers from integrating verbal and graphic information, has been associated with poor learning outcomes (Mason et al., 2013, 2015).

According to Scheiter et al. (2017), this ineffective processing is an obstacle that limits the efficacy and benefits of using multiple representations. Researchers have attributed this processing to several factors. Among them is the fact that graphic information is processed much more rapidly than a written text representation. This in turn gives readers the false impression of fully understanding the diagram, leading them to predominantly attend to the text representation (Scheiter et al., 2017; Schroeder et al., 2011). Another contributing factor is the possibility that readers do not have the skills and strategies to process the graphics effectively, leading them to attend to the graphics only for a short period of time (Hochpöchler et al., 2013).

Although it has been established that readers tend to process multi-representational materials in the domain of science and language learning in a heavily text-based fashion, 
relatively little is known about how L2 learners who are still acquiring the language process other expository materials. The first research objective of this paper is therefore to determine whether ESL learners would demonstrate the same processing of text and diagram that has previously been observed in the domains of science and L2 learning. Eye tracking data were collected and analyzed for this purpose. The second research objective intends to explore the reasons behind the ESL learners' processing. Since eye tracking data cannot offer insights into why a particular representation is processed (or not processed), retrospective interviews were conducted for this purpose.

In the Malaysian context, the number of studies that examine the reading processes of Malaysian learners using the eye tracking methodology has steadily increased in recent years. The methodology is used in research across different areas of studies, for instance, to examine the processing of literal versus metaphorical expressions in Malay (Tengku \& Salehuddin, 2020), graphic novels in English (Mohd Yusof et al., 2020) and science terminologies in Mandarin (Soh, 2017). Local eye-tracking studies have also evolved to incorporate retrospective interview data as a methodological triangulation strategy (Warid Mihat et al., 2018) as exemplified in Sulaiman et al. (2020). However, we are not aware of any studies that explore the reading processes of Malaysian ESL learners while reading science texts with graphics. Ideally, graphics contribute to learners' comprehension of science texts, however, they are usually underused, leading to poor comprehension. The present study examines to what extent this phenomenon can be extended to the ESL learners' reading of a similar material.

\section{METHOD}

\section{PARTICIPANTS}

A total of 28 first-year undergraduates from the Faculty of Social Sciences and Humanities participated in this study. All participants were native speakers of the Malay language and were, at the time of study, enrolled in an English for Academic Purposes course at the university. Prior to this course, the students had already been exposed to 11 years of formal learning of English language in schools. The sample comprised ESL learners from low and average levels of English proficiency as determined by their performance in the Malaysian University English Test (MUET), a national English language proficiency test for university admissions. The low proficient learners in the sample scored either band 1 or 2 in MUET whereas the average proficient learners scored either band 3 or 4 . Coincidentally, none of the 28 participants scored band 5 or 6 in MUET (high proficient). All learners had normal or corrected-to-normal visions and were given a small monetary reward as a token of appreciation for their participation.

\section{MATERIAL}

The reading material used as the stimulus was a science passage describing the pathway of human's fear response system. It was adapted from the Scientific American magazine (LeDoux, 1994) and contained 160 words. Its readability score was 40.6 (Flesch Readability Ease Formula), and therefore, was classified as difficult. Its Flesch-Kincaid grade level, however, was 12.5, indicating that it was suitable for undergraduates' reading. Accompanying this was a diagram illustrating the pathway of the fear response system and the corresponding parts of the brain. These corresponding parts were labelled accordingly in the diagram. The layout of this stimulus is presented in Figure 1. The actual stimulus is not shown due to copyright issues. 


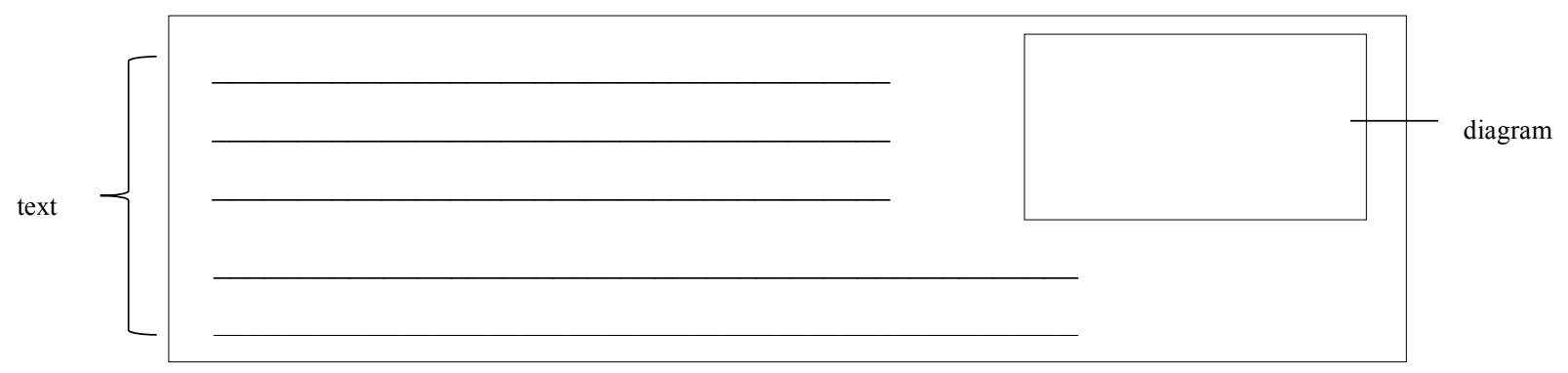

FIGURE 1. Layout of the stimulus

The diagram can be categorized as a process diagram which depicts the relationships and processes among objects (Lohse et al., 1994). The diagram also serves to organize the complex content of the passage into a more coherent and succinct framework, therefore, making it more coherent to readers (Levin et al., 1987). The stimulus was presented on a single page on a computer screen.

\section{APPARATUS AND EYE TRACKING MEASURES}

An EyeNTNU-120 eye tracker with a sampling rate of $120 \mathrm{~Hz}$ and 0.3 -degree angle error was used to collect the eye tracking data. It has two infrared light-emitting diodes (LEDs) that reflect on the cornea of the left eye to detect eye movements. The output energy of the LEDs is $3.5 \mathrm{~mW} / \mathrm{cm} 2$ at a working distance of $4 \mathrm{~cm}$. For analysis, the reading material was segmented into two regions of interest (ROIs); one text ROI and one graphic ROI (see Figure 1). An ROI is a region of a visual stimulus for which eye tracking measures are established and data are gathered (Scheiter \& Eitel, 2017). Since the total surface region occupied by the text region was more than half of the region occupied by the diagram, eye tracking measures had to be expressed as proportional values. This was necessary because the larger text region might be attended to longer than the graphic region simply because of differences in size. Hence, to measure the participants' distribution of attention across text and graphic regions, proportion of total fixation duration (TFD) was used. TFD sums up the time for all fixations on a particular ROI. Proportion of TFD on the text region was computed by dividing the TFD on the text region with TFD on the overall stimulus. For proportion of TFD on the graphic region, TFD on the graphic was divided with TFD on the overall stimulus.

\section{PROCEDURE}

The data collection involves two stages. The first stage concerns the reading of the science passage conducted on 28 participants. This was an individual session and took place in an eye tracking laboratory at the participants' faculty. Upon their arrival at the laboratory, the participants were first briefed about the study and its objectives. Once their informed consent was gained, they were asked to complete a background questionnaire containing eight questions. The participants were then asked to sit in front of the mounted eye tracker and placed their chin on a chin rest to minimize their head movements. Next, they took part in a practice trial which was conducted to ensure that the participants would become familiar with the procedures involved (Yoo \& Lee, 2013). In this practice trial, the participants were presented with a science passage on the respiratory system and a corresponding diagram similar (in terms of the design and arrangement of representations) to the one they would be exposed to in the actual reading stage. Once the practice trial was completed, a two-minute break ensued, followed by the actual reading stage. The participants read the science passage on the fear response system at their own pace. After reading, they completed a short comprehension task 
consisting of five yes/no questions. This was done by pressing one of two keys on the keyboard; ' $z$ ' for 'yes' and ' $m$ ' for 'no'. All five questions were presented individually on the screen and the program did not allow the participants to return to either the passage or previously presented questions. This first stage took about 20 to 30 minutes.

One week after the eye tracking session, nine participants were randomly chosen and invited to take part in a short retrospective interview (i.e., the second stage of data collection). This interview was one part of a larger study conducted to explore reasons and factors underlying their processing patterns. For this paper, we would focus on the learners' reasoning for attending (or not attending) to the diagram in the science passage and questioned them about their reading strategies. All interviews took place in the same eye tracking laboratory. The interviewees were allowed to communicate in either Malay or English and the interviewer posed questions in the interviewee's preferred language.

\section{FINDINGS AND DISCUSSION}

\section{EYE TRACKING ANALYSIS}

To address the first research objective, a paired sample t-test was performed. Mean proportion of TFD on the text region was $0.94(S D=0.08)$, much higher than the mean proportion of TFD on the graphic region, i.e. $0.06(S D=0.08)$. This difference was significant, $t(27)=28.30, p$ $<.001$, and the effect size was large, $d=10.99$. This result indicates that the ESL learners spent their reading time on the text region of the reading material significantly longer, i.e., $94 \%$ of total reading time. In contrast, they spent very little time, i.e., only $6 \%$ of total reading time on the graphic region. Descriptive statistics further revealed that $39 \%$ of the learners (11 of them) did not even look at the diagram.

Based on the findings above, it could be concluded that the strategy used by the ESL learners in processing the science passage was heavily text-based. It was similar to the strategy that L1 readers used in processing science materials (Hannus \& Hyönä, 1999; SchmidtWeigand et al., 2010) and the strategy that L2 learners used in processing L2 learning materials (Bisson et al., 2014; Tragant Mestres \& Pellicer-Sánchez, 2019; Warren et al., 2018). Given the important pedagogical function that the particular diagram serves in relation to the text, the strategy exhibited here is rather worrying.

These findings also suggest that the ESL learners had neglected the diagram and the benefits of having two different forms of representations were not materialized. The analysis of the retrospective interviews in the next section would attempt to identify the reasons for this phenomenon.

\section{RETROSPECTIVE INTERVIEW ANALYSIS}

There are multiple reasons as to why a reader fails to process a diagram sufficiently. Among them is the false impression of understanding graphics. Readers process graphic information much more rapidly than a written text representation, hence giving them an illusion of fully understanding the graphics (Scheiter et al., 2017; Schroeder et al., 2011). The following analysis examined whether this proposition, among others, is also applicable to the ESL learners interviewed in this study. Extracts of the interviews are presented and italicized. Since the interviewees were allowed to use both Malay and English, the Malay extracts were translated into English in this paper.

During the retrospective interviews, the learners were asked to describe their reading strategy. Here, the learners' reasoning for attending (or not attending) to the diagram in the science passage was examined. 
Two of the interviewees, Interviewees 2 and 4 admitted that they neglected the diagram when reading the science passage.

\section{Excerpt 1}

I knew that I should use both diagram and text, however, I focused on (the) text because there were a lot of difficult words. [Interviewee 2]

\section{Excerpt 2}

I read the text first then looked at the diagram... I did it (read the text) twice and I referred to the text a lot (because I) did not find the diagram helpful. [Interviewee 4]

Based on the interviews, both Interviewee 4 and especially Interviewee 2, appeared to struggle with the text region due to its low readability ease level. This difficulty led them to predominantly attend to the text region in an attempt to comprehend the text. As a result, the diagram was ignored (but not abandoned) to the point that Interviewee 4 found it unhelpful. In this case, there is a high possibility that the diagram did not benefit both participants due to their lack of English proficiency.

The remaining interviewees found the diagram helpful. These can be seen from the following excerpts.

\section{Excerpt 3}

It is easier for me to understand the whole context of the passage by referring to the diagram. The diagram helped a lot in understanding the passage. [Interviewee 5]

Similar to Interviewee 5, Interviewee 1 also reported that the diagram helped her in understanding the passage.

\section{Excerpt 4}

I looked at the text first. I don't know, maybe by reading, I'd have the mental image first. After that, I looked at the diagram... text first and then (the) diagram helped me understand better. [Interviewee 1]

Interviewee 1's attempt to read and understand the text content first was echoed by several other interviewees.

\section{Excerpt 5}

I mostly switched back and forth, like the text first followed by the diagram, textdiagram, text-diagram. That's how I did it to understand what the text is saying... For me, I'd try to understand the text first and if I didn't understand it, I'd refer to the diagram because I am not from the science faculty. [Interviewee 3]

\section{Excerpt 6}

I read the text first because the text explains the diagram... The diagram is very helpful. If the diagram is not enough, the text will explain. [Interviewee 9]

The comments in Excerpts 4, 5, 6 and 7 (see below) are not at all dissimilar from the strategy described by Hegarty and Just (1993) whereby most readers would first read or reread the text and process it extensively to construct a global understanding of the material content. In detailing this strategy, Hegarty and Just noted that once information is integrated at a textbased level, readers would then construct a spatial mental model by using the diagram as an 
aid. To do this, readers switched between the text and the diagram back and forth. The utilization of this strategy can be seen from Excerpt 5 shown earlier and is even more evident from Interviewee 7's excerpt below:

\section{Excerpt 7 \\ I read the text and diagram back and forth as I found this easier. I'd focus on one then find the (corresponding) keywords in the other... The diagram partially helped in understanding the passage. [Interviewee 7]}

Based on the interview excerpts above, it appears that the participants used two distinct processing strategies. The first strategy is to concentrate on the text and neglect the diagram as in the case of Interviewees 2 (Excerpt 1) and 4 (Excerpt 2). The second strategy that most of the interviewees claimed to adopt is to use the diagram as an aid to comprehend the text and the passage in general.

Having said that, it was disconcerting to see a mismatch between the analyses of the interview data and the eye tracking data. Although majority of the interviewees claimed they found the diagram to be helpful in understanding the difficult text, the eye tracking analysis revealed that that the ESL learners spent very little time on the diagram and a few did not even look at it. What is the cause of this mismatch? It is postulated here that most of the ESL learners knew the correct strategy to read science texts with diagrams but did not practice it to the extent that some did not even know that they had neglected the diagram.

Based on the answers that the interviewees provided when asked about their reading strategy, we labeled their strategy as either text-diagram, or text-only. An interviewee would be said to employ the text-diagram strategy if they mentioned looking at both the text and the diagram. If they mentioned looking only at the text, they would be said to employ the text-only strategy. These strategies were listed in the second column of Table 1. As shown, all the interviewees claimed they were using the text-diagram strategy but in reality (as revealed by the eye tracking analysis in the final column), three of them used the text-only strategy. The rest did use the text-diagram strategy but the extent they referred to the diagram would most probably be minimal as evinced in the paired-sample t-test results presented earlier.

TABLE 1. Categorization of interview participants based on their reading strategy

\begin{tabular}{ccc}
\hline Interviewee & $\begin{array}{c}\text { Reading Strategy } \\
\text { Assumed }\end{array}$ & $\begin{array}{c}\text { Reading Strategy Identified from } \\
\text { Eye Tracking Data }\end{array}$ \\
\hline 1 & Text-diagram & Text-diagram \\
2 & Text-diagram & Text-only \\
3 & Text-diagram & Text-diagram \\
4 & Text-diagram & Text-only \\
5 & Text-diagram & Text-only \\
6 & Text-diagram & Text-diagram \\
7 & Text-diagram & Text-diagram \\
8 & Text-diagram & Text-diagram \\
9 & Text-diagram & Text-diagram \\
\hline
\end{tabular}

The fact that all interviewees claimed they were using the text-diagram strategy suggests that they were aware that was a useful strategy to employ. However, it would seem that majority of them were so occupied with the text that they did not take advantage of the presence of the diagram in the passage. Several design principles may therefore be useful to encourage these readers to pay more attention to graphics. Colour-coding and deictic expressions, for instance, can cue and guide them to switch attention from text to corresponding parts in the graphics. Figure 2 provides an example of a hypothetical passage that uses colour- 
coding. The passage consists of an explanatory text and a diagram illustrating the concept explained in the passage. Key concepts, i.e., XXX and XYZ, in the text and diagram are linked by means of colour-coding. Each concept in the text is assigned a colour and the corresponding unit in the diagram is assigned a label with the same colour.

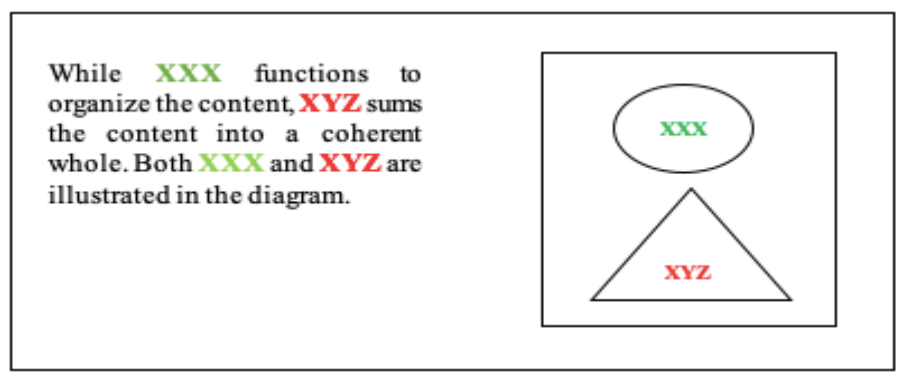

FIGURE 2. An example of colour-coding

\section{CONCLUSION}

This paper set out to determine how ESL learners process a science passage that incorporates textual and graphic input in English. Through analysis of the learners' eye fixations, we learned that these ESL learners heavily processed the textual input in the form of the science passage as opposed to the graphic input in the form of a diagram as found in earlier studies. The findings revealed that their attempts to understand the text motivated the ways in which they processed the material. Most of the interviewees appreciated the inclusion of the diagram as they found it helpful. However, difficulty in understanding the text likely drove most students to focus mainly on the text. A more interesting phenomenon was that all the students claimed they were using the text-diagram strategy suggesting that all of them were aware that it was a useful strategy. Unfortunately, many of these students were so engrossed with the difficult text that they did not put the diagram to good use.

Although this paper has provided insights into how ESL learners processed a multirepresentational expository material in English, some limitations nevertheless need to be outlined. Firstly, the characteristic of the reading material, i.e., its readability ease was rather low for this group of ESL learners. Future research could therefore make use of materials with a higher readability ease or, alternatively, involved more proficient English learners to read materials that are with a higher readability ease. Secondly, the way readers process a reading material is rather dependent on several characteristics such as their prior knowledge in the subject matter, their reading comprehension ability (in both L1 and L2), and their spatial ability. None of these individual characteristics were considered in the analysis. Future research would do well in examining the role of these individual differences in explaining readers' processing of similar materials. Additionally, the comprehension task comprising five yes/no questions might be too simplistic to measure learning outcome effectively. Hence there is a need to design a more sophisticated instrument such as including open-ended questions or a drawing task to achieve this purpose. Finally, although we have supplemented the eye tracking data with retrospective interviews, we recommend future research to play the recording of participants' eye movements when they were reading the stimulus. This stimulated recall technique would help them recall and verbalize their thought processes while they are watching the recording.

To conclude, although the eye tracking data imply that ESL learners lack the awareness and strategy to read and process expository texts in English effectively, proponents of multiple representations can still take comfort in the fact that many of the learners do realize the potential and benefits of processing graphics for overall comprehension. 


\section{REFERENCES}

Bartholomé, T., \& Bromme, R. (2009). Coherence formation when learning from text and pictures: What kind of support for whom? Journal of Educational Psychology. 101(2), 282-293. https://doi.org/10.1037/a0014312

Bisson, M.-J., Van Heuven, W. J. B., Conklin, K., \& Tunney, R. J. (2014). The role of verbal and pictorial information in multi-modal incidental acquisition of foreign language vocabulary. The Quarterly Journal of Experimental Psychology. 68(7), 1306-1326. https://doi.org/10.1080/17470218.2014.979211

Carpenter, S. K., \& Olson, K. M. (2012). Are pictures good for learning new vocabulary in a foreign language? only if you think they are not. Journal of Experimental Psychology: Learning, Memory, and Cognition. 38(1), 92-101. https://doi.org/10.1037/a0024828

Hannus, M., \& Hyönä, J. (1999). Utilization of illustrations during learning of science textbook passages among low- and high-ability children. Contemporary Educational Psychology. 24(2), 95-123. https://doi.org/http://dx.doi.org/10.1006/ceps.1998.0987

Hegarty, M., \& Just, M. A. (1993). Constructing mental models of machines from text and diagrams. Journal of Memory and Language. 32(6), 717-742. https://doi.org/http://dx.doi.org/10.1006/jmla.1993.1036

Hochpöchler, U., Schnotz, W., Rasch, T., Ullrich, M., Horz, H., McElvany, N., \& Baumert, J. (2013). Dynamics of mental model construction from text and graphics. European Journal of Psychology of Education. 28(4), 1105-1126. https://doi.org/10.1007/s10212-012-0156-z

LeDoux, J. E. (1994). Emotion, memory and the brain. Scientific American. 270(6), 50-57.

Levin, J. R., Anglin, G. J., \& Carney, R. N. (1987). On empirically validating functions of pictures in prose. The Psychology of Illustration. 1, 51-86.

Lohse, G. L., Biolsi, K., Walker, N., \& Rueter, H. H. (1994). A classification of visual representations. Communications of the ACM. 37(12), 36-49.

Mason, L., Tornatora, M. C., \& Pluchino, P. (2013). Do fourth graders integrate text and picture in processing and learning from an illustrated science text? Evidence from eyemovement patterns. Computers \& Education. 60(1), 95-109. https://doi.org/http://dx.doi.org/10.1016/j.compedu.2012.07.011

Mason, L., Tornatora, M., \& Pluchino, P. (2015). Integrative processing of verbal and graphical information during re-reading predicts learning from illustrated text: an eye-movement study. Reading and Writing. 28(6), 851-872. https://doi.org/10.1007/s11145-0159552-5

Mohd Yusof, S., Mohd Lazim, Z., Salehuddin, K., \& Mohamad Shahimin, M. (2020). Graphic novels: Understanding how fifth graders read literary text through eye movement analysis. Kritika Kultura. 33/34, 388-427.

Pellicer-Sanchez, A., Tragant, E., Conklin, K., Rodgers, M., Llanes, A., \& Serrano, R. (2018). L2 reading and reading-while-listening in multimodal learning conditions: An eyetracking study. ELT Research Papers 18.01. British Council.

Perez, M. M., Van Den Noortgate, W., \& Desmet, P. (2013). Captioned video for L2 listening and vocabulary learning: A meta-analysis. System. 41(3), 720-739.

Plass, J. L., \& Jones, L. C. (2005). Multimedia learning in second language acquisition. In R. E. Mayer, (Ed.). The Cambridge Handbook of Multimedia Learning (pp. 467-488). New York: Cambridge University Press.

Rau, M. A. (2017). Conditions for the effectiveness of multiple visual representations in enhancing STEM learning. Educational Psychology Review. 29(4), 717-761. https://doi.org/10.1007/s10648-016-9365-3 
Rayner, K. (2009). Eye movements and attention in reading, scene perception, and visual search. The Quarterly Journal of Experimental Psychology. 62(8), 1457-1506. doi: $10.1080 / 17470210902816461$

Renkl, A., \& Scheiter, K. (2015). Studying visual displays: How to instructionally support learning. Educational Psychology Review. 29(3), 599-621. https://doi.org/10.1007/s10648-015-9340-4

Scheiter, K., \& Eitel, A. (2017). The use of eye tracking as a research and instructional tool in multimedia learning. In C. A. Was, F. J. Sansosti, \& B. J. Morris, (Eds.). Eye-tracking Technology Applications in Educational Research (pp. 143-164). Hershey, PA: IGI Global.

Scheiter, K., Schüler, A., \& Eitel, A. (2017). Learning from multimedia: Cognitive processes and instructional support. In S. Schwan \& U. Cress (Eds.). The Psychology of Digital Learning Constructing, Exchanging, and Acquiring Knowledge with Digital Media (pp. 1-19). Cham: Springer.

Schmidt-Weigand, F., Kohnert, A., \& Glowalla, U. (2010). A closer look at split visual attention in system- and self-paced instruction in multimedia learning. Learning and Instruction. 20(2),

$100-110$. https://doi.org/http://dx.doi.org/10.1016/j.learninstruc.2009.02.011

Schroeder, S., Richter, T., McElvany, N., Hachfeld, A., Baumert, J., Schnotz, W., Horz, H., \& Ullrich, M. (2011). Teachers' beliefs, instructional behaviors, and students' engagement in learning from texts with instructional pictures. Learning and Instruction. 21(3), 403-415. https://doi.org/https://doi.org/10.1016/j.learninstruc.2010.06.001

Soh, O. K. (2017). Processing academic science reading texts through context effects: Evidence from eye movements. EURASIA Journal of Mathematics, Science and Technology Education. 13(3), 771-790.

Stieff, M., Hegarty, M., \& Deslongchamps, G. (2011). Identifying representational competence with multi-representational displays. Cognition and Instruction, 29(1), 123-145. https://doi.org/10.1080/07370008.2010.507318

Sulaiman, N. A., Salehuddin, K., \& Khairudin, K. (2020). Reading English academic texts: Evidence from ESL undergraduates' eye movement data. 3L: Language, Linguistics, Literature ${ }^{\circledR}$. 26(1), 60-78

Tengku, Fariqul Haq \& Salehuddin, K. (2020). Pembacaan ungkapan literal dan metafora Melayu: Satu kajian penjejakan mata (Reading Malay literal and metaphorical expressions: An eye tracking study). GEMA Online ${ }^{\circledR}$ Journal of Language Studies. 20(2), 18-35.

Tragant Mestres, E., \& Pellicer-Sánchez, A. (2019). Young EFL learners' processing of multimodal input: Examining learners' eye movements. System. 80, 212-223. https://doi.org/10.1016/j.system.2018.12.002

Warid Mihat, Hazita Azman, \& Soh, O. K. (2018). Bringing reading research in multilingual Nusantara into a new direction through eye-tracking. Journal of Nusantara Studies (JONUS). 3(2), 107-123.

Warren, P., Boers, F., Grimshaw, G., \& Siyanova-Chanturia, A. (2018). The effect of gloss type on learners'intake of new words during reading: Evidence from eye-tracking. Studies in Second Language Acquisition. 40(4), 883-906.

Yoo, D. G., \& Lee, J. (2013). Using contextual information in learners' spoken language communication: An eye-tracking study. GEMA Online ${ }^{\circledR}$ Journal of Language Studies.13(2), 5-20. 


\section{ABOUT THE AUTHORS}

Nurjanah is a lecturer at the Centre for Research in Language and Linguistics, Universiti Kebangsaan Malaysia. Her research focuses on the use of multiple representations (especially text and graphics) in learning by second language speakers. She primarily uses the eye-tracking methodology in her research.

Thang Siew Ming is a Professor at HELP University and also an Honorary Professor at the Faculty of Social Sciences and Humanities, Universiti Kebangsaan Malaysia. Her areas of interest are CALL, Learner Autonomy, Motivation, and Eye-tracking research. She is President of PacCALL and Co-chair of GLoCALL series of conferences. 